\title{
Burbot Early Life History Strategies in the Great Lakes
}

\author{
David J. Jude* \\ School of Natural Resources, University of Michigan, 440 Church Street, Ann Arbor, \\ Michigan 48109, USA
}

\section{Yu Wang}

School of Freshwater Sciences, University of Wisconsin-Milwaukee, 600 East Greenfield Avenue, Milwaukee, Wisconsin 53203, USA

\author{
Stephen R. Hensler \\ School of Natural Resources, University of Michigan, 440 Church Street, Ann Arbor, \\ Michigan 48109, USA
}

\author{
John Janssen \\ School of Freshwater Sciences, University of Wisconsin-Milwaukee, 600 East Greenfield Avenue, \\ Milwaukee, Wisconsin 53203, USA
}

\begin{abstract}
Burbot Lota lota exhibit four previously known reproductive strategies in the Great Lakes region. In this paper we review those strategies and provide evidence for a fifth one-delayed deepwater spawning. The four known, shallow-water strategies are as follows: (1) spawning by self-sustaining, landlocked populations, (2) spawning in tributaries in winter and the exit of larvae to a Great Lake, (3) spawning by residents in a spawning stream with access to a Great Lake, and (4) spawning on unconsolidated and rocky areas in shallow water in winter in the lake proper. Resident, landlocked populations exist in some Michigan and Wisconsin rivers (e.g., the Muskegon River in Michigan). The evidence for winter tributary spawning is the appearance of newly hatched Burbot in the St. Marys and Bark rivers during April-June. Evidence for Burbot juveniles leaving spawning streams is U.S. Fish and Wildlife Service tributory mouth trap data. The evidence for winter nearshore spawning comes from power plant monthly entrainment studies (Mansfield et al. 1983). Our proposed fifth strategy is spring and summer spawning at deep reefs, where there is probably cobble or boulder habitat. Our evidence comes from midlake reefs in Lake Michigan and offshore areas of Lake Huron: (1) we collected adult Burbot at midlake reefs in Lake Michigan, (2) we collected many Burbot larvae (many of which were newly hatched) from Lakes Michigan and Huron in June-August, and (3) we collected a Burbot egg in a PONAR grab in mid-July from 73 m in southern Lake Huron. An important question remains, namely, which life history strategy provides the highest recruitment success for this species. It may be that adaptability ensures the survival of this important, top-predator fish during periods of crisis (e.g., encounters with dams, Sea Lamprey Petromyzon marinus predation).
\end{abstract}

Burbot Lota lota occupy the widest range of depths of Great Lakes basin fishes, ranging from anthropogenically and perhaps historically landlocked populations in small streams to fish occupying depths of at least $300 \mathrm{~m}$ (Boyer et al. 1989) in the Great
Lakes. In Lake Baikal (Siberia), their depth range is given as ranging from tributaries to $200 \mathrm{~m}$ (Sideleva 2003). There are two other Great Lakes fish with such a wide range in depths: the Slimy Sculpin Cottus cognatus, which inhabits cold streams and

*Corresponding author: djude@umich.edu

Received September 10, 2012; accepted April 6, 2013 
the Great Lakes but whose densities diminish with depth, and Lake Trout Salvelinus namaycush, which is found from great depths within the Great Lakes to some lakes inland. This range of depth and habitat means that their life histories must be suitable for diverse ecological conditions. The early life histories of Burbot differ dramatically from those of most other fishes, since Burbot eggs and larvae are very small and semibuoyant, a strategy consistent with that of all other members of the Gadidae family, all of which are marine. However, some species, such as the Atlantic Tomcod Microgadus tomcod, are anadromous.

Burbot are important ecologically as keystone predators. They are top predators in all five Great Lakes and therefore important ecologically for the roles they play as consumers of prey and potential competitors with other predators like Lake Trout (Martin and Olver 1980). Recently, Burbot have been switching from native prey to Round Goby Neogobius melanostomus on shallow reefs (Hensler et al. 2008; Jacobs et al. 2010). Since Burbot eat sculpins (Cottus spp. and Deepwater Sculpin Myoxocephalus thompsonii; Fratt et al. 1997), which are egg predators (Wojcik et al. 1982), and Burbot are known Lake Trout egg and fry predators (Stauffer and Wagner 1979; Jones et al. 1995; Janssen et al. 2006), their abundance may impact Lake Trout egg survival on spawning reefs (Janssen et al. 2007). Unlike the other deepwater top predator, Lake Trout, Burbot were not largely extirpated due to Sea Lamprey Petromyzon marinus predation in the Great Lakes in the 1950s and this may be related to their spawning in diverse habitats. Burbot are known to spawn in rivers (Bjorn 1939; Jude et al. 1998), in the Great Lakes (December-January: Lake Michigan; March-April: Lake Erie; and February-March: Lake Superior), and in Canadian inland lakes as well as Lake Constance, Germany. Prior to the present study it has been assumed that they spawn from January to March (Auer et al. 1982; Donner and Eckmann 2011). However, in Lake Constance spawning can be delayed until the end of May, when water temperatures rise to $5.6^{\circ} \mathrm{C}$ (Fischer 1999). Because the Great Lakes are slow to warm, it is possible that spawning in deepwater, should it occur, is also delayed.

Burbot eggs are small $(1.3-1.8 \mathrm{~mm})$ and are broadcast randomly at night by adults that form writhing masses during reproduction (Scott and Crossman 1973). Eggs are semibuoyant when first spawned, then become demersal. The larvae hatch at around 3-4 mm (Auer 1982), rise to the surface to fill their air bladders, and have to initiate feeding 6-9 d posthatching (Fischer 1999). In the Great Lakes larval Burbot undergo a diel vertical migration (Oyadomari and Auer 2004), presumably to avoid predation, to pursue migrating prey, and/or for energetic optimization (Donner and Eckmann 2011). They are initially pelagic, then go through a settlement phase at around $21 \mathrm{~mm}$ or less at about $68 \mathrm{~d}$; they settle to the bottom, then migrate along the profundal zone (16 m maximum depth for Oneida Lake and $250 \mathrm{~m}$ for Lake Constance) toward shore, where they presumably stay (Clady 1976; Fischer 1999; Hoffman and Fischer 2001).

Water temperature and the currents in the Great Lakes are likely critical factors that affect Burbot survival. The spawning and recruitment strategy of larval fish is influenced by water temperature (Cushing 1982; Steele 1985; Cardinale et al. 2008; Kallasvuo et al. 2010), which in turn affects the productivity of zooplankton prey and larval fish predators, such as Alewives Alosa pseudoharengus (Madenjian et al. 2002). In addition, currents can impact the success of larval fishes by transporting them to areas that are optimal (or not) for survival (e.g., Yellow Perch Perca flavescens; Beletsky et al. 2007). As far as currently recorded, Burbot exhibit four early life history strategies: (1) adults come from the Great Lakes or major rivers to spawn in tributaries in winter (fish larvae are then transported from the tributaries to a Great Lake; Scott and Crossman 1973; Jude et al. 1998); (2) adults from the Great Lakes spawn in tributaries in winter, but the larvae remain there and may or may not return to a Great Lake as juveniles (D. J. Jude, unpublished data); (3) populations that are landlocked (with maximum sizes much smaller than those of Great Lakes fish) are self-sustaining, spawning where they occur (Dixon and Vokoun 2009; Seelbach and Wiley 1997); and (4) adults spawn on rocky and unconsolidated substrates in a Great Lake in winter (Scott and Crossman 1973). In this paper we review the known life history strategies of Burbot. We explore the spring distribution of Burbot during thermal bar formation and stratification on Lake Michigan midlake reefs, examine potential differences between the east and west sides of Lake Michigan as tributary sources of Burbot larvae, and document a new spawning behavior in hypolimnetic waters in spring and summer.

\section{METHODS}

Because Burbot are generally not target species for fishery management, collections usually do not specifically target them; as a result, our specimens were largely bycatch obtained during other projects or from general surveys.

Density of adult Burbot at Lake Michigan's midlake reef complex.-Adult Burbot are common to abundant among boulders at two subreefs of the midlake reef complex (MLRC): Sheboygan Reef (about $43^{\circ} 20.5^{\prime} \mathrm{N},-87^{\circ} 09^{\prime} \mathrm{W}$ ) and East Reef (about $43^{\circ} 01^{\prime} \mathrm{N},-87^{\circ} 21^{\prime} \mathrm{W}$ ) in southern Lake Michigan (see Figure 1 and Janssen et al. 2006 for map). Our only attempt at quantification was at East Reef as a byproduct of searching for and collecting Lake Trout fry using a remotely operated vehicle (ROV) modified for electroshocking Lake Trout fry (described in Janssen et al. 2006). The sampling date was August 6, 2009, and the ROV had recently been outfitted with a GPS tracking system that allowed mapping.

Offshore larval fish and egg collections. - A 1-m $\times 2-\mathrm{m}$ neuston net with $500-\mu \mathrm{m}$ mesh was used in duplicate at several standard U.S. Environmental Protection Agency (EPA) monitoring stations in Lake Michigan (Figure 1; Barbiero and Tuchman 2001, 2004, 2009); the net was deployed in the top $2 \mathrm{~m}$ of water during 2007 and 2008 during day and night, depending on arrival time at each station. The net was towed at $1-2 \mathrm{~m} / \mathrm{s}$ and was equipped with a Rigosha flowmeter. Samples were preserved in ethanol. Fish larvae were removed from the sample 


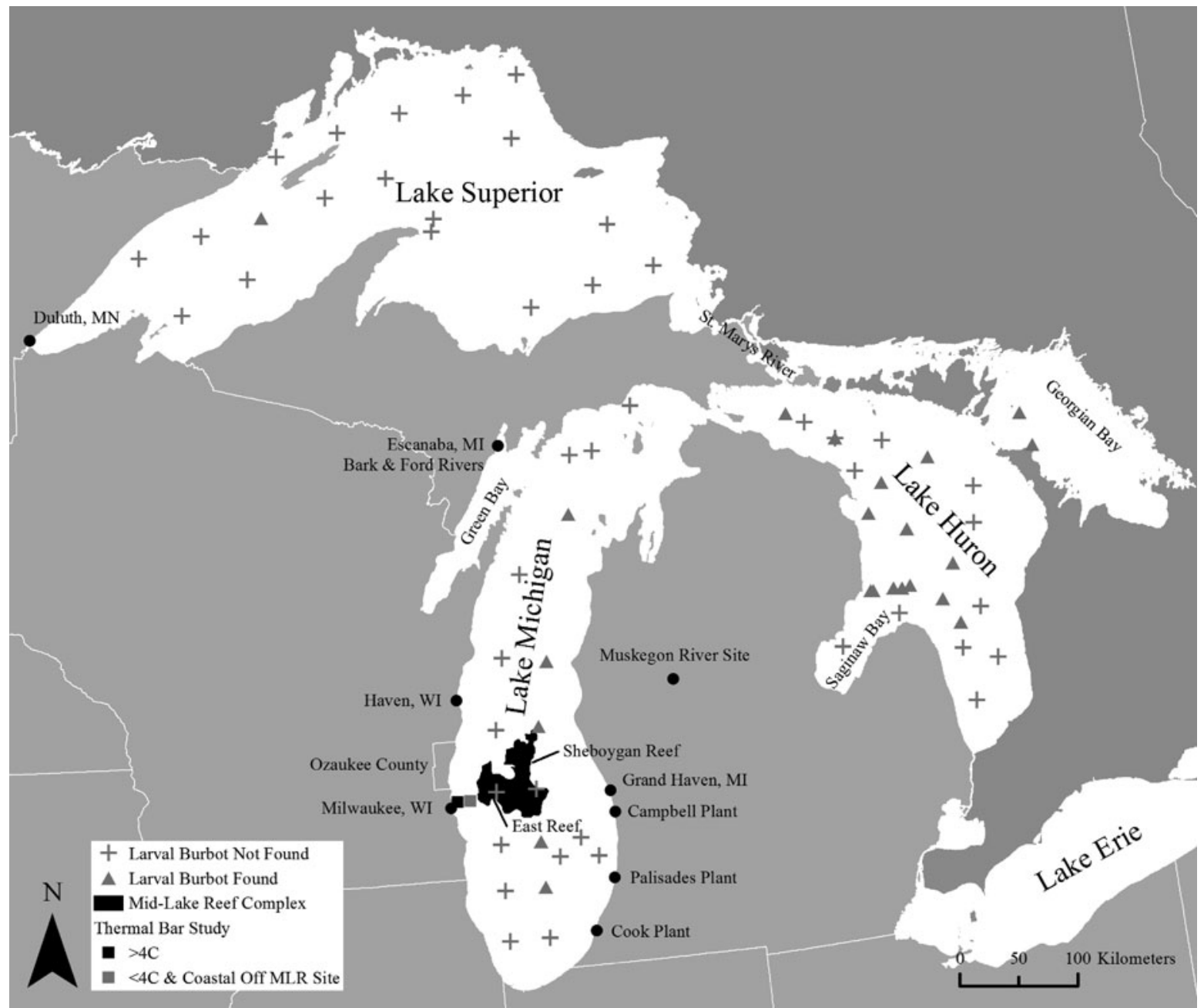

FIGURE 1. Map of Lakes Michigan, Huron, and Superior showing the standard EPA monitoring stations (plus signs and triangles), the various towns and sites mentioned in the text, and the location of the midlake reef complex in southern Lake Michigan.

in the laboratory, counted, measured to the nearest $0.1 \mathrm{~mm}$, and identified following Auer et al. (1982). Larval fish were also saved from the routine EPA monitoring of zooplankton and crustaceans Mysis spp. during surveys on Lakes Michigan, Huron, and Superior during 2007-2008. Briefly, zooplankton and rotifers were collected at about 20 stations per lake (Figure 1; and see Barbiero and Tuchman 2001, 2002, 2004) using a $153-\mu \mathrm{m}$-mesh net (100 $\mathrm{m}$ deep, vertical tow) and $63-\mu \mathrm{m}$-mesh net (20 m deep, vertical tow), respectively, at each station. Samples were preserved in a $10 \%$ formaldehyde solution. Mysis tows were only conducted at night using a 1$\mathrm{m} \times 1-\mathrm{m}, 500-\mu \mathrm{m}-\mathrm{mesh}$ net that narrowed to a panel of $250 \mu \mathrm{m}$ on the bottom. The net was lowered to within 3-5 m of the bottom and towed vertically to sample the entire water column.

During 2007-2009, sampling was also conducted at night along transects in Lake Michigan on both sides of the thermal bar off Milwaukee, Wisconsin (in a variety of locations from $43^{\circ} 05^{\prime} \mathrm{N},-87^{\circ} 50^{\prime} \mathrm{W}$ to $43^{\circ} 05^{\prime} \mathrm{N},-87^{\circ} 42^{\prime} \mathrm{W}$; Figure 1) using a 1.4-m-wide $\times 2$-m-deep Tucker trawl equipped with $500-\mu \mathrm{m}$ mesh (Wang et al. 2012). Sampling was conducted on April 23 and May 3, 4, and 7, 2007; April 17, 21, and 28 and May 5, 2008; and April 28 and May 4 and 14, 2009. The procedures of Rice et al. (1987), Nash and Geffen (1991), Geffen and Nash (1992), and Dettmers et al. (2005) were followed. As the thermal bar moved offshore, so did the transects and depths sampled (the nearshore transect depth increased from 17 to $37 \mathrm{~m}$; the offshore depths increased from 39 to $78 \mathrm{~m}$ ). We used a stepwise, oblique tow starting at $10 \mathrm{~m}$ deep, with a $1-\mathrm{m}$ rise every 3 min (30- min tow). Samples were stored in 95\% ethanol. Fish larvae were removed, identified, and measured to the nearest millimeter. If the sample size was $>100$, a subsample was taken using a Folsom plankton splitter, such that a sample of 100 or less was processed and TLs measured for the length-frequency analysis. A General Oceanics flowmeter mounted in the center of the net allowed calculation of water volume and larval fish densities. 
At the MLRC stations on Lake Michigan, sampling was conducted during the day at two locations with similar bottom depths-coastal (55-62 m deep; $43^{\circ} 01.3404^{\prime} \mathrm{N}$, $-87^{\circ} 42.4820^{\prime} \mathrm{W}$ to $\left.43^{\circ} 01.6125^{\prime} \mathrm{N},-87^{\circ} 43.1299^{\prime} \mathrm{W}\right)$ and East Reef $\left(55-60 \mathrm{~m}\right.$ deep; $\left.43^{\circ} 01.5703^{\prime} \mathrm{N},-87^{\circ} 21.1581^{\prime} \mathrm{W}\right)$-from 2007 to 2009 (Figure 1). Reef locations were about $27 \mathrm{~km}$ offshore of the coastal location. East Reef, which is composed of bedrock with a cobble and sand veneer, rises from a depth of $100 \mathrm{~m}$ or more (see Janssen et al. 2006 for the bathymetry of its western face). The target species was Bloater Coregonus hoyi larvae, which are near the surface during the day. We used the same Tucker trawl and sampling steps and procedures as used with the thermal bar transect sampling (Wang et al. 2012). Sampling was conducted on six dates: June 25 and July 6, 2007; June 23 and July 1, 2008; and June 18 and July 14, 2009. Two-way analysis of variance (ANOVA) was used with date and location as factors to compare the larval fish density and size of Burbot between these two locations.

During July 9-12, 2012, a 0.75-m-diameter, 571- $\mu \mathrm{m}$-mesh net equipped with a Rigosha flowmeter was deployed at 15 sites throughout Lake Huron (see Table 1 for GPS coordinates) using a stepped-oblique protocol for $10 \mathrm{~min}$ for each tow at an average speed of $1.3 \mathrm{~m} / \mathrm{s}$ on the EPA vessel Lake Guardian. The tow consisted of deploying the net with a depressor to 20, 15,10, and $5 \mathrm{~m}$ as well as the surface for $2 \mathrm{~min}$ each (for some stations that were $<20 \mathrm{~m}$ we modified the protocol to sample the entire water column). Samples were preserved in ethanol. In addition, a standard PONAR grab sampler was deployed at the same 15 stations to sample fish eggs.

Spawning and hatching date calculations for larval Burbot.-We calculated the probable spawning and hatching dates for four size-classes $(4,9,10$, and $15 \mathrm{~mm})$ of larval Burbot collected in mid-July and mid-August to estimate spawning times during nonwinter months, which have not been documented for the Great Lakes. Spawning date back-calculations were based on the findings of a 32-d incubation period at $4^{\circ} \mathrm{C}$ (Jäger et al. 1981) and a 30-40-d incubation period at $4-5^{\circ} \mathrm{C}$ (Donner and Eckmann 2011); there was a 70-d incubation period for Burbot eggs if they were in $0-1.5^{\circ} \mathrm{C}$ temperatures (McCrimmon 1959; Muth 1973), which would occur during winter in most rivers and nearshore zones of the Great Lakes. We choose an incubation period of $35 \mathrm{~d}$ at $4-5^{\circ} \mathrm{C}$ as a compromise value. If spawning occurred during stratification, the water temperatures on the bottom would be expected to be near $4-5^{\circ} \mathrm{C}$. We measured bottom temperatures in Lake Huron on July 12 at $4.3^{\circ} \mathrm{C}$. To determine the hatching date, we calculated the number of days that a given-sized larva was alive based on length-at-age data from Lake Constance (Fischer 1999). We back-calculated

TABLE 1. Details of Burbot larvae collected in EPA routine surveys ( $\mathrm{ZP}=$ zooplankton tows, $\mathrm{MY}=$ Mysis tows) and additional fish larvae tows (FL) done during 2007-2008 in Lakes Michigan (MI), Huron (HU), and Superior (SU). Individual lengths of each fish larva caught are given under length.

\begin{tabular}{|c|c|c|c|c|c|c|}
\hline Date & $\begin{array}{c}\text { EPA } \\
\text { station }^{\mathrm{a}}\end{array}$ & $\begin{array}{l}\text { Sample } \\
\text { type }\end{array}$ & $\begin{array}{c}\text { Station } \\
\text { depth (m) }\end{array}$ & $\begin{array}{c}\text { Sample } \\
\text { depth (m) }\end{array}$ & $\begin{array}{l}\text { Length } \\
(\mathrm{mm})\end{array}$ & $\begin{array}{c}\text { Density } \\
\left.\text { (no./1,000 } \mathrm{m}^{3}\right)\end{array}$ \\
\hline \multicolumn{7}{|c|}{ Spring } \\
\hline 17 Apr 2008 & MI 34 & FL & 159 & 1 & 9.5 & 1 \\
\hline 18 Apr 2008 & MI 47 & FL & 191 & 1 & 6 & 1 \\
\hline \multicolumn{7}{|c|}{ Summer } \\
\hline 2 Aug 2007 & MI 11 & MY & 126 & 124 & 5,5 & 16 \\
\hline 1 Aug 2007 & MI 18 & $\mathrm{ZP}$ & 160 & 100 & 5.5 & 51 \\
\hline 5 Aug 2007 & HU 61 & MY & 118 & 116 & $5.5,5.5$ & 17 \\
\hline 20 Aug 2007 & SU 16 & $\mathrm{ZP}$ & 178 & 100 & $15,8.5$ & 102 \\
\hline 4 Aug 2007 & HU 32 & $\mathrm{ZP}$ & 83 & 81 & 3 & 63 \\
\hline \multirow[t]{2}{*}{5 Aug 2007} & HU 48 & $\mathrm{ZP}$ & 112 & 100 & 4.5 & 51 \\
\hline & HU 54 & $\mathrm{ZP}$ & 124 & 100 & 5 & 51 \\
\hline 1 Aug 2008 & MI 11 & $\mathrm{ZP}$ & 125 & 100 & 6.5 & 51 \\
\hline \multirow[t]{4}{*}{2 Aug 2008} & MI 27 & $\mathrm{ZP}$ & 104 & 100 & 5 & 51 \\
\hline & MI 18 & MY & 160 & 157 & 8 & 6 \\
\hline & MI 27 & MY & 104 & 101 & 7,8 & 20 \\
\hline & MI 18 & MY & 160 & 157 & 8 & 6 \\
\hline 6 Aug 2008 & HU 97 & MY & 43 & 40 & $13.5,13.5$ & 50 \\
\hline \multirow[t]{3}{*}{7 Aug 2008} & HU 27 & MY & 56 & 54 & 14.5 & 19 \\
\hline & HU 95 & MY & 68 & 65 & 9,9 & 31 \\
\hline & HU 27 & MY & 55 & 52 & 14.5 & 19 \\
\hline \multirow[t]{2}{*}{6 Aug 2008} & HU 45 & $\mathrm{ZP}$ & 98 & 96 & $5,7.5,6,4.5,4$ & 212 \\
\hline & HU 37 & $\mathrm{ZP}$ & 74 & 71 & 4 & 72 \\
\hline
\end{tabular}

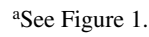


its hatching date by going back in time that many days from the collection date. Lake Constance is a large, deep oligotrophic lake comparable to Lakes Michigan and Huron with respect to its thermal cycle. Burbot grew slowly during the first $23 \mathrm{~d}$ of life (average calculated value, $0.084 \mathrm{~mm} / \mathrm{d}$ ) but faster thereafter $(0.57 \mathrm{~mm} / \mathrm{d})$. Using this data, a 4-9-mm Burbot larva collected in July and August in the Great Lakes would be from 1 to $29 \mathrm{~d}$ old, while a 10-15-mm larva would be 30-39 d old.

\section{RESULTS}

\section{Offshore Larval Fish Collections}

Burbot larvae were collected in Lakes Superior (small sample), Michigan, and Huron during spring and summer 20072008; these fish had a mean density of $124 / 1,000 \mathrm{~m}^{3}$ (Table 1) and ranged in size from 3 to $15 \mathrm{~mm}$ (Figure 2). The vertical zooplankton and Mysis tows showed that Burbot were present during both the spring and summer cruise periods. Newly hatched 3-4-mm individuals were present during August, demonstrating that spawning had occurred later in the year, a deviation from winter spawning behavior. Based on 90-160 degree-days to hatch in $4{ }^{\circ} \mathrm{C}$ water and the fact that fish larvae may not show an increment on the otolith for $2 \mathrm{~d}$ (Fischer 1999), we estimated that these larvae were spawned sometime between May 22 and June 19.

\section{Nearshore and Midlake Reef Collections}

Adult Burbot at the midlake reef complex.-On August 6, 2009, we extracted 13 adult Burbot from dense, multilayered boulder cover in an area approximating $1,500 \mathrm{~m}^{2}$. This density (about $1 / 100 \mathrm{~m}^{2}$ ) should be considered minimal because Burbot were not the target species, sampling in the area was not spatially comprehensive, and we could only see Burbot affected by the

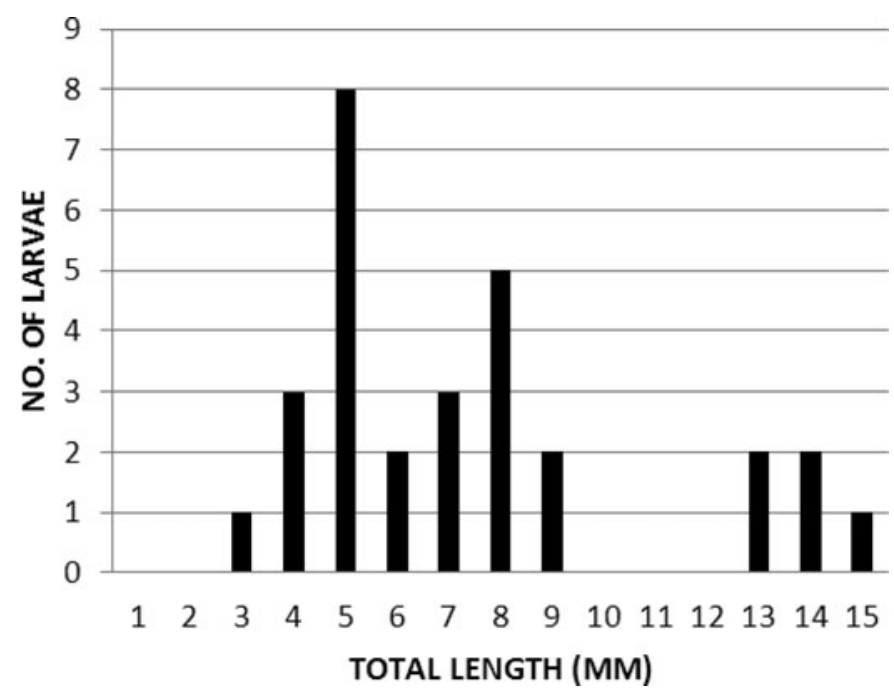

FIGURE 2. Length-frequency distribution of larval Burbot collected in Mysis and zooplankton vertical tows as part of the EPA monitoring program in Lakes Michigan, Huron, and Superior, 2007-2008. electroshocker. Burbot deep within the layers of the boulders were likely missed. The Burbot observed via ROV on Julian's Reef (23-41-m deep) in southern Lake Michigan had a similar density of 1.4/100 $\mathrm{m}^{2}$ (Edsall et al. 1993).

Larval Burbot distribution during thermal bar formation.We sampled for larval Burbot off Milwaukee on the western side of Lake Michigan (Figure 1) during thermal bar formation in spring. Inside the thermal bar, sampling depths increased from 17 to $37 \mathrm{~m}$ (2.4-10.0 $\mathrm{km}$ from shore) as the bar moved offshore. The depths of the offshore locations increased from 39 to $78 \mathrm{~m}$ (8.0-18.9 km from shore). Sampling occurred within $\left(>4^{\circ} \mathrm{C}\right)$ and outside the bar $\left(<4^{\circ} \mathrm{C}\right)$ three to four times during April 17May 14, 2007-2009 to determine whether thermal conditions or prey densities favored the survival of Burbot larvae. No Burbot larvae were found during these studies despite our collecting 11 samples ( $5.5 \mathrm{~h}$ of sampling effort), suggesting that no spawning occurred in the local tributaries to Lake Michigan on the western side; no resident Burbot populations exist in these streams either (Becker 1983).

Larval Burbot distribution around the midlake reefs.-We collected 4,074 Burbot larvae in Tucker trawls during JuneJuly 2007-2009 (length range, 3.4-14 $\mathrm{mm}$ ) at East Reef and the coastal site (Figure 1); many Burbot larvae were newly hatched. We aged eight Burbot larvae that were 3-4 mm long and found that they averaged $3 \mathrm{~d}$ old. Densities were significantly higher on the reef $\left(6-221 / 1,000 \mathrm{~m}^{3}\right)$ than in the coastal area $(5-$ $55 / 1,000 \mathrm{~m}^{3}$ ) (Figure $3 ; F_{1,5}=13.6, P=0.014$ ). Date was marginally significant $\left(F_{5,5}=4.9, P=0.052\right)$.

Total lengths of larval Burbot were compared between coastal locations and the MLRC using two-way ANOVA, with the factors being sampling date and location (Figure 4). The samples from June 25, 2007, were accidentally dehydrated, so we deleted that date from the length-frequency analysis. Larval Burbot lengths were $\log _{10}$-transformed prior to analysis. The ANOVA showed a statistically significant interaction between date and location $\left(F_{4,356}=3.03, P=0.018\right)$, so the main effects were not interpretable. The post hoc test (Dunnett's test comparing the lengths at the two locations by date, for five pairwise comparisons) showed that the MLRC Burbot larvae were significantly smaller than the coastal larvae on July 6, $2007(P<$ $0.05)$ and June $23,2008(P=0.01)$. There were no statistically distinguishable differences in length between sites for the other three dates. While this is a mixed result, it is consistent with larval Burbot originating at or near the MLRC and then drifting away.

\section{Lake Huron Collections}

Distribution and density of Burbot larvae.-Larval Burbot were collected from Lake Huron during July 9-12, 2012, to determine the spatial and length distributions throughout the lake (Figure 1). From 0 to 14 larval Burbot were collected at the 15 stations sampled, with the highest density being observed in Georgian Bay (Table 2). Densities ranged from 0 to $255 / 1,000 \mathrm{~m}^{3}$, while total lengths ranged from 4 to $13 \mathrm{~mm}$. There 


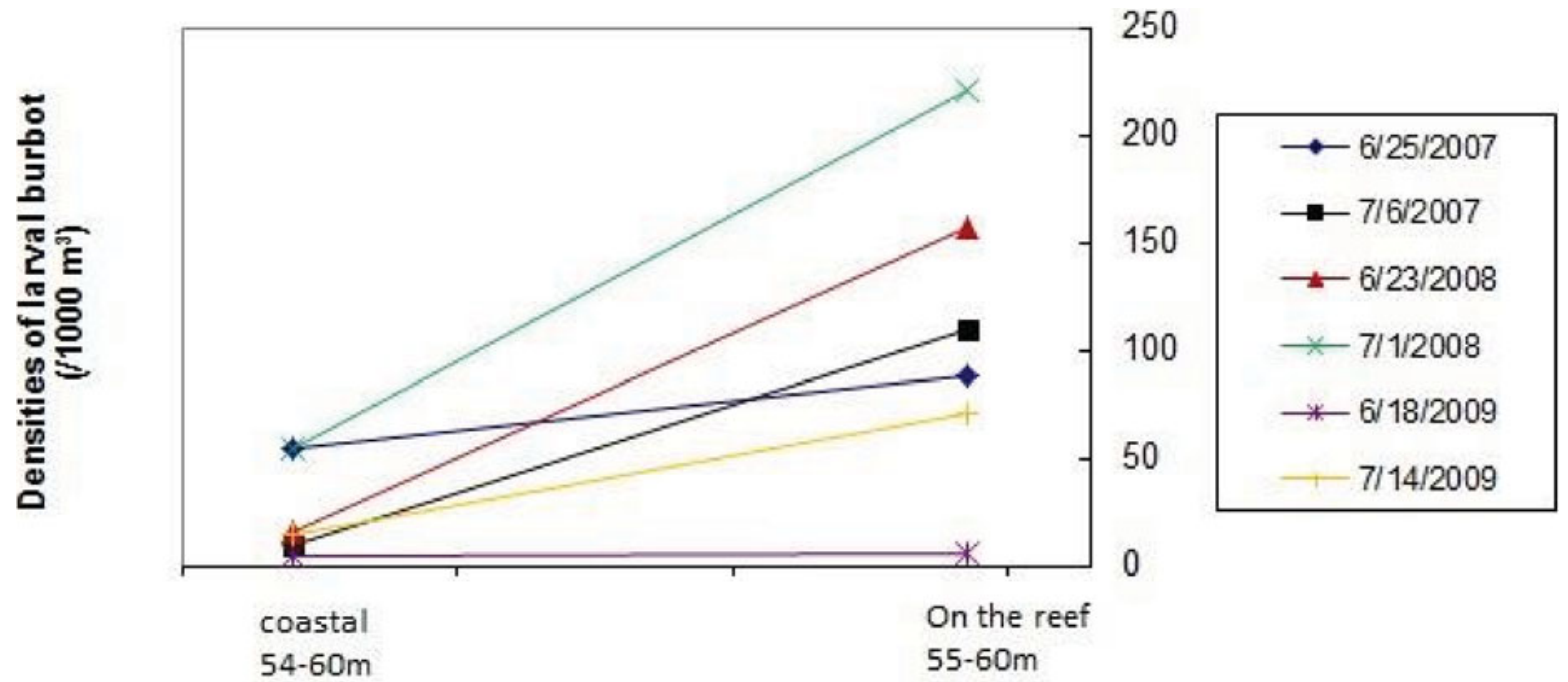

Location

FIGURE 3. Densities of Burbot larvae along the eastern coast (about 50-60 m bottom depth) and on East Reef (midlake reef complex; depth range, 52-83 m) during June-July 2007-2009 in southern Lake Michigan. The two locations are separated by about $27 \mathrm{~km}$, and the bottom depth adjacent to East Reef is $>100 \mathrm{~m}$. [Figure available in color online.]

did not seem to be any trends in density across Lake Huron, except that no Burbot were found in eutrophic Saginaw Bay or the shallow station USGS 17 just outside the bay (in contrast to the deeper station in Georgian Bay, which had the highest density of all stations sampled). More Burbot were collected during the day $\left(255 / 1,000 \mathrm{~m}^{3}\right)$ than at night $\left(59 / 1,000 \mathrm{~m}^{3}\right)$ at the Georgian Bay site. Presence of newly hatched fish larvae in the 4-mm range suggested recent hatching by Burbot in Lake Huron. These larvae had to have originated from spawning in offshore Lake Huron in early spring, since the incubation of eggs at $4-5^{\circ} \mathrm{C}$ takes approximately $30-40 \mathrm{~d}$ (Jäger et al. 1981; Donner and Eckmann 2011), making the spawning date around June 3-13.

Burbot lengths and spawning times.-Our length-frequency data from the Lake Michigan midlake reefs (Figure 4), together with those from the EPA collections from Lakes Michigan and Huron (Figure 2) and those from Lake Huron in 2012 (Table 2) during June-August show two cohorts, one composed of newly hatched and young individuals (4-9 $\mathrm{mm}$ ) and one composed of larger individuals $(10-15 \mathrm{~mm})$. Based on the incubation times

TABLE 2. Details of Burbot larvae collected during July 9-12, 2012 in Lake Huron in the top $20 \mathrm{~m}$ with 10-min tows with a 0.75 -m-diameter, 500- $\mu \mathrm{m}$-mesh plankton net. See Figure 1 and Barbiero et al. (2009) for station descriptions. Station designations: D = day; N = night.

\begin{tabular}{llrrrr}
\hline Station & \multicolumn{2}{c}{ GPS coordinates } & No. & Density & Size range (mm) \\
\hline HU 37 & $44.7610^{\circ} \mathrm{N}$ & $-82.7829^{\circ} \mathrm{W}$ & 8 & 146 & $7-11$ \\
USGS 40 & $44.3295^{\circ} \mathrm{N}$ & $-83.2255^{\circ} \mathrm{W}$ & 1 & 18 & 11 \\
USGS 73 & $44.3188^{\circ} \mathrm{N}$ & $-82.9192^{\circ} \mathrm{W}$ & 1 & 18 & 11 \\
USGS 64 & $44.3277^{\circ} \mathrm{N}$ & $-83.0073^{\circ} \mathrm{W}$ & 4 & 73 & $9-12$ \\
USGS 17 & $44.3317^{\circ} \mathrm{N}$ & $-83.2527^{\circ} \mathrm{W}$ & 0 & 0 & 13 \\
SAG BAY & $43.9420^{\circ} \mathrm{N}$ & $-83.6237^{\circ} \mathrm{W}$ & 0 & 0 & $5-12$ \\
HU 27 & $44.1982^{\circ} \mathrm{N}$ & $-82.5040^{\circ} \mathrm{W}$ & 1 & 18 & 6 \\
HU 15 & $44.0000^{\circ} \mathrm{N}$ & $-82.3500^{\circ} \mathrm{W}$ & 7 & 121 & $6-9$ \\
HU 93 & $44.0993^{\circ} \mathrm{N}$ & $-82.1173^{\circ} \mathrm{W}$ & 2 & 48 & $4-8$ \\
HU 32 & $44.4532^{\circ} \mathrm{N}$ & $-82.3417^{\circ} \mathrm{W}$ & 3 & 55 & $8-11$ \\
G. BAY 1-D & $45.3043^{\circ} \mathrm{N}$ & $-81.2399^{\circ} \mathrm{W}$ & 14 & 255 & $6-7$ \\
G. BAY 1-N & $45.3043^{\circ} \mathrm{N}$ & $-81.2399^{\circ} \mathrm{W}$ & 5 & 59 & $9-11$ \\
G.BAY 2-D & $45.7600^{\circ} \mathrm{N}$ & $-81.1878^{\circ} \mathrm{W}$ & 2 & 70 & $7-8$ \\
HU 48 & $45.2778^{\circ} \mathrm{N}$ & $-82.4521^{\circ} \mathrm{W}$ & 2 & 23 & $6-11$ \\
HU 53 & $45.4492^{\circ} \mathrm{N}$ & $-82.9159^{\circ} \mathrm{W}$ & 8 & 205 & 180 \\
HU 45 & $45.1333^{\circ} \mathrm{N}$ & $-82.9833^{\circ} \mathrm{W}$ & 8 & & \\
\hline
\end{tabular}



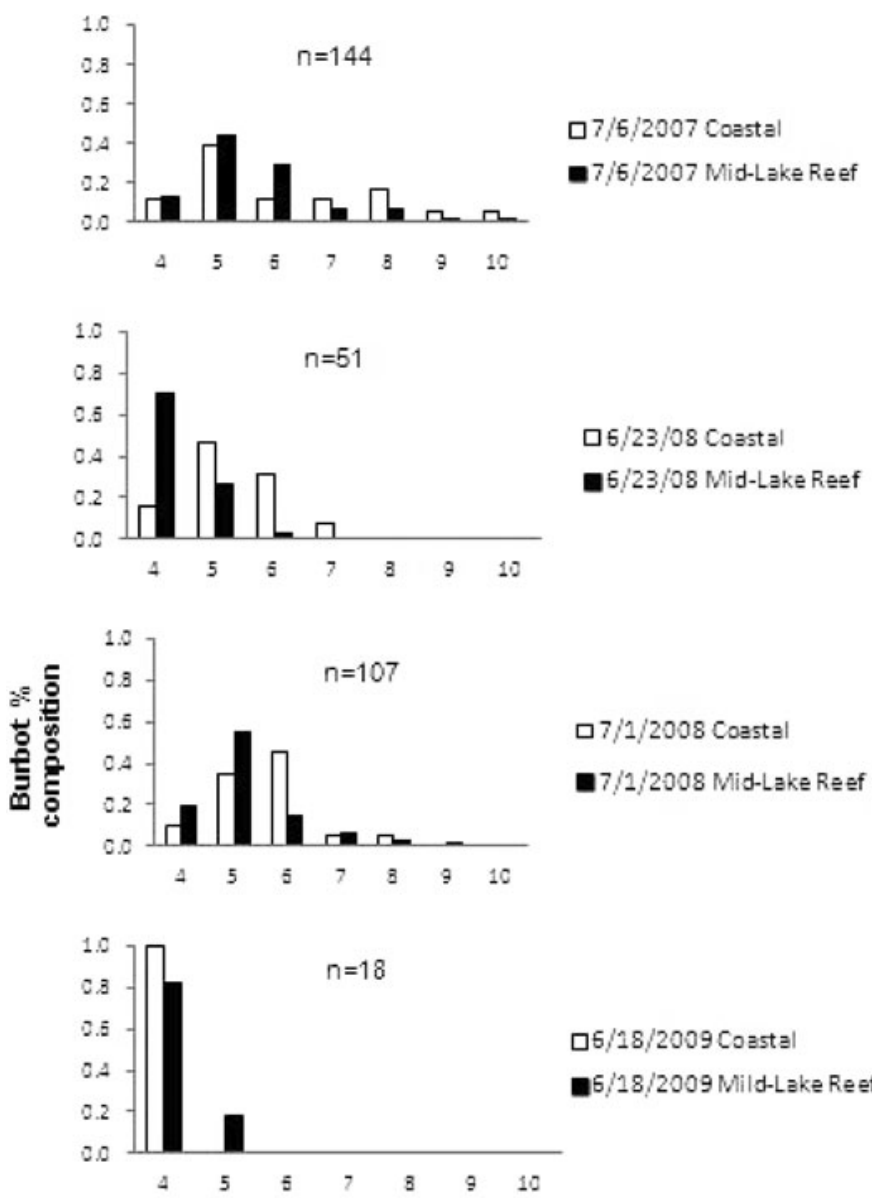

ㄱ $7 / 1 / 2008$ Coasta

/1/2008 Mid-Lake Reef

Q6/18/2009 Coasta

6/18/2009 Mild-Lake Reef

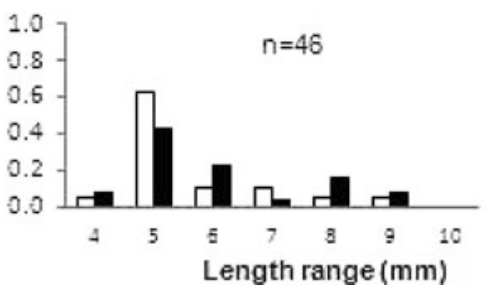

口7/14/2009 Cossta

7/14/2009 Mid-Lake Reef

FIGURE 4. Length frequency histograms for larval Burbot collected at coastal and midlake reef sites on two sample dates/year during 2007-2009 (Figure 1).

at $0-1.5^{\circ} \mathrm{C}$ and $4-5^{\circ} \mathrm{C}$, the 4-mm Burbot collected in mid-July and mid-August would have been spawned sometime during the period May 5-July 5, while 9-mm Burbot collected during midAugust would have been spawned sometime during the period May 9-June 13 (Figure 5). Even some of the larger larvae (10$15 \mathrm{~mm}$ ) collected in mid-July, would have been spawned during May 3-11 if the eggs incubated in $4-5^{\circ} \mathrm{C}$ water, while all of the 10-15-mm larvae collected in mid-August under either regime would have been spawned over the period April 29-June 11.

\section{Egg Deposition Nearshore and Offshore in Lakes Michigan and Huron}

Closest to shore, Burbot eggs were found during January in the eastern Lake Michigan beach zone near Port Sheldon,

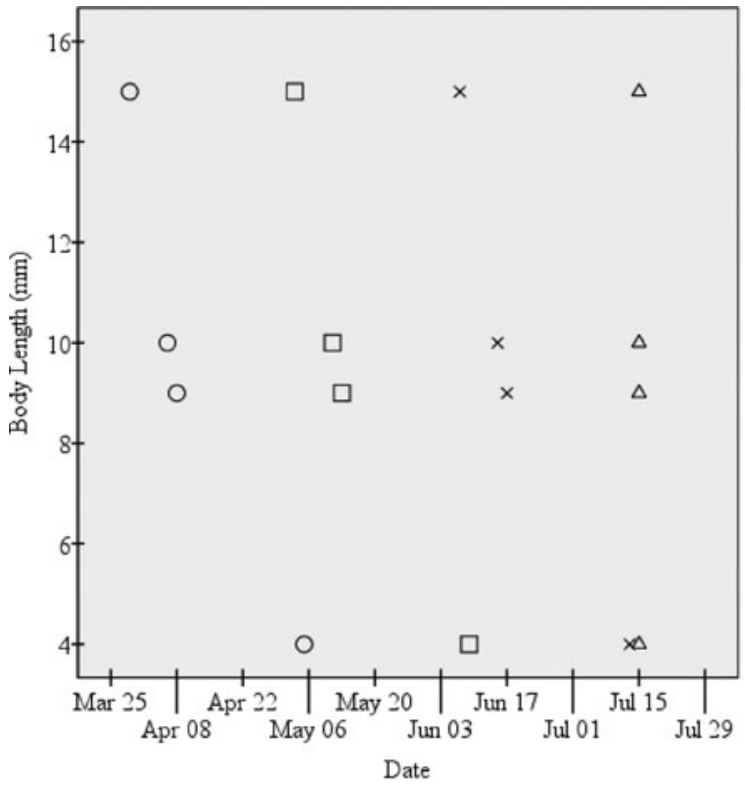

Life:Stage

O Spawn-70

$\square$ Spawn-35

$\times$ Hatch

$\Delta$ Collected

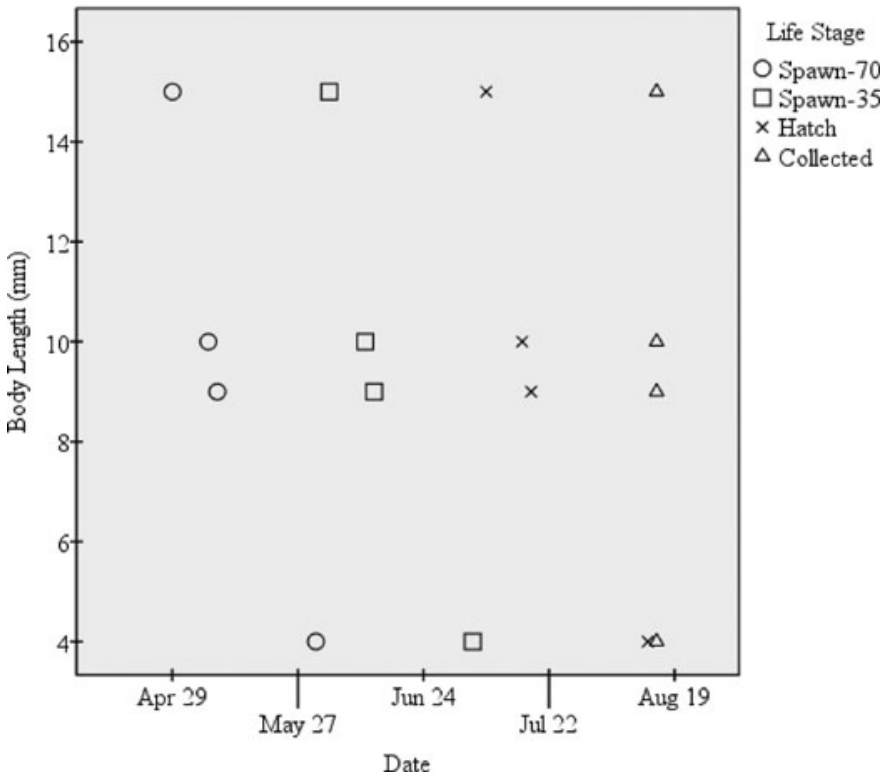

FIGURE 5. Sizes of Burbot larvae (4, 9, 10, and $15 \mathrm{~mm})$ collected during midJuly (top panel) and mid-August (bottom panel) and their possible spawning dates ( $x$-axes; spawn-70 $=$ based on an incubation time of $70 \mathrm{~d}$ at $0-1.5^{\circ} \mathrm{C}$ [McCrimmon 1959]; spawn $35=$ based on an incubation time of $35 \mathrm{~d}$ at $4-5^{\circ} \mathrm{C}$ [Jäger et al. 1981; Donner and Eckmann 2011]). An age-length key generated using growth estimates from Fischer (1999) was used to estimate the number of days from the collection date (triangles) to the hatching date (cross symbols) (see Methods).

Michigan. The water temperature was $0.4^{\circ} \mathrm{C}$ (Jude et al. 1979). An egg was found in a PONAR sample collected on July 12, 2012, in southern Lake Huron (EPA station HU 32; Table 1), where the depth was $73 \mathrm{~m}$ and the water temperature was $4.3^{\circ} \mathrm{C}$. This egg was subsequently excised and the embryo inside was identified as a Burbot. Assuming that this egg was spawned in and remained in $4{ }^{\circ} \mathrm{C}$ water, it would take approximately $30-40 \mathrm{~d}$ 
to hatch (Jäger et al. 1981; Donner and Eckmann 2011), making its approximate spawning date June 3-13, 2012. This is evidence of spawning offshore in the middle of the southern basin of Lake Huron during times undocumented in the literature.

Burbot eggs were also identified in the diet of three Slimy Sculpins by genetic analyses. Fish were sampled in a single trawl haul offshore of Frankfort, Michigan, at $128 \mathrm{~m}$ on April 20, 2010 (J. Londer, personal communication, U.S. Geological Survey [USGS], Ann Arbor, Michigan). As Slimy Sculpins are benthic with a small home range, these data also document probable Burbot spawning in early spring in deep waters of Lake Michigan.

\section{DISCUSSION}

\section{Documented Burbot Spawning Strategies}

There appear to be four major life history strategies that Burbot use to overcome environmental and biological obstacles to survival. First, Burbot spawn during winter in tributaries and remain in rivers that often extend $>200 \mathrm{~km}$ upstream from a Great Lake. We also documented with field sampling, distribution records for Michigan (Bailey et al. 2004) and Wisconsin (Becker 1983), and survey records of the Michigan Department of Natural Resources (MDNR) (Bassett and Kramer 2009; Bassett and Herman 2009), and the Michigan Rivers Inventory (Seelbach and Wiley 1997) that juvenile and adult Burbot (generally $<300 \mathrm{~mm}$ ) are widespread throughout the state of Michigan and in northern Wisconsin, especially around Green Bay. Michigan DNR Burbot collections from the Ford River made during electroshocking surveys during August 2009 at three sites near Hendersen $\left(46.10863^{\circ} \mathrm{N}, 87.84127^{\circ} \mathrm{W}\right)$ showed that Burbot ranged from 76 to $229 \mathrm{~mm}(N=53$; A. Abrahamson, MDNR, personal communication). This site is approximately $224 \mathrm{~km}$ from the mouth of the river, which runs into Green Bay near Escanaba, Michigan. These populations appear to be self-sustaining, and some are landlocked by dams. For example, on August 4, 2011, we electroshocked 25 juvenile Burbot from the Muskegon River near Hersey, Michigan, that were 65$210 \mathrm{~mm}$ long (Jude, unpublished data). Interestingly, this section of the river (Osceola County: T17NR9WS11) is isolated by two dams and happened to have been treated with rotenone by the MDNR for fish assessment (those data also show an abundance of Burbot in the system during August 5, 1993; MDNR 1993); 397 Burbot were collected that ranged from 71 to $270 \mathrm{~mm}$. These sizes (maximum near $300 \mathrm{~mm}$ ) appear to be typical of these landlocked populations. Dixon and Vokoun (2009) studied Burbot in the Hoosatonic River in Connecticut, collecting fish from 84 to $356 \mathrm{~mm}$; the fish were mature at 2 years old, and none $>500 \mathrm{~mm}$ were seen. Lake Superior fish are mature at $280 \mathrm{~mm}$ (Bailey 1972), so these fish appear to be mature enough to spawn around $300 \mathrm{~mm}$. In contrast, no juvenile or adult Burbot have been reported in adjacent streams or rivers along the western shore in southern Lake Michigan. However, juveniles and adults were present farther north in Green Bay
(Becker 1983) and Burbot larvae were found around Ozaukee County and Haven, Wisconsin (Mansfield et al. 1983), which are about $90 \mathrm{~km}$ from Milwaukee, where some of our midlake sampling occurred.

Another question arising from this study is whether spawning Burbot from Lake Michigan ascend rivers like the Ford River (which has no dams), where juvenile Burbot have been found $224 \mathrm{~km}$ upstream, or whether these juveniles are the result of local spawning by nonmigrating residents. Spatial segregation can lead to speciation. Genetic studies would help to unravel this conundrum.

We believe that some juvenile Burbot, especially those close to a Great Lake, employ a second life history strategy, leaving the tributary in which they were spawned and returning to the lake rather than spending their entire lives in the tributary. Sea Lamprey traps placed in many tributary mouths by the U.S. Fish and Wildlife Service (USFWS) during spring catch juvenile Burbot (J. Slade and D. Keffer, USFWS, personal communication), which suggests that some juveniles exit tributaries.

In the third strategy, spawning occurs during winter in rivers and streams, with larvae exiting in large numbers during AprilMay. The evidence for this is the appearance of larvae in lateMarch-May samples in Lake Michigan near tributaries (Mansfield et al. 1983) and the appearance of 4-mm larvae from April 26 through May 30 in the St. Marys River (Jude et al. 1998). Data obtained offshore from the Ford River in 2012 showing high densities of 4-5-mm Burbot confirm ongoing spawning in northern Lake Michigan (J. Schaeffer, USGS, personal communication). The lack of Burbot in Wisconsin streams corresponds with the lack of Burbot larvae from our thermal bar studies, which contrasts starkly with the eastern side of Lake Michigan, where there are Burbot in streams and high densities of Burbot larvae in nearshore waters.

In the fourth strategy, spawning occurs during winter in nearshore and offshore sites (including unconsolidated sites and those with rocky substrates). The evidence for this includes the discovery of Burbot eggs in the nearshore zone of eastern Lake Michigan during January (Jude et al. 1979) and in the stomachs of Slimy Sculpin captured at $128 \mathrm{~m}$ offshore of Frankfort, Michigan, on April 20, 2010 (J. Londer, personal communication). In addition, most published information on Burbot documents this type of spawning in most of the areas of the Great Lakes where Burbot occur (McCrimmon 1959; Bailey 1972; Muth 1973; Scott and Crossman 1973).

Lastly, we documented spawning at nearshore and offshore sites in the hypolimnion during spring and summer in Lakes Michigan and Huron. There is no evidence that any spawning by Burbot occurred in tributaries during this time. We based this new finding on the appearance of large numbers of newly hatched Burbot on the midlake reefs in late June-August 20072009 , which argues for spawning there later in the year than has been documented in the Great Lakes and rivers, e.g., late AprilMay (Scott and Crossman 1973; Mansfield et al. 1983). We base this deduction on four lines of evidence. First, we routinely see 
and collect adult Burbot on the reefs, as did Edsall et al. (1993). Second, we collected 4,074 Burbot larvae in Tucker trawls from June 18 to July 14, 2007-2009, many of which were newly hatched, and more were collected on the reefs than in nearshore waters. Third, these results were corroborated by the appearance of many newly hatched Burbot larvae in the EPA's zooplankton and Mysis samples collected during August 2007-2009 at several stations (43-190 m) in Lakes Michigan and Huron. Fourth, the calculation of spawning and hatching times based on published incubation times (McCrimmon 1959; Jäger et al. 1981) and growth rates (Fischer 1999) clearly show that spawning and hatching occurred later than published winter spawning dates, some in June and early July. These spawning times are far removed from published spawning times of December-March (Bjorn 1939; Mansfield et al. 1983; Nash and Geffen 1991; Jude et al. 1998). These authors showed that there is a pulse of newly hatched Burbot larvae from winter spawning from late March through June, with peaks in May and lesser numbers of fish being collected in June. These changes are not due to climate change, since studies have shown that there have been no long-term temperature trends in Lake Michigan over recent time (McCormick and Fahnenstiel 1999). Using the 70-d incubation temperatures at $0-1.5^{\circ} \mathrm{C}$ of McCrimmon (1959) would suggest Burbot larvae collected during the peak mid-May pulse were spawned with a midpoint of March 5. Mansfield et al. (1983) concluded that 3-4-mm Burbot from northern Lake Michigan collected in June were spawned in March or early April.

Finally, the discovery of a Burbot egg in a PONAR sample from $73 \mathrm{~m}$ in Lake Huron on July 12 corroborated midlake spawning during stratification. Interestingly enough, Bailey (1972) reported that Burbot collected in late January and February from nearshore Lake Superior were spent; however, those collected offshore had not spawned in January and March, suggesting spawning later in the year.

These combined findings document spawning by Burbot on the midlake reefs and deep offshore sites in spring and summer; the same probably occurs on other, similar reefs in the Great Lakes and provides more reproductive diversity for enhancing survival. A similar finding of late spawning (Burbot larvae collected in August) was made by Donner and Eckmann (2011) and Probst and Eckmann (2009a) in Lake Constance. This behavior provides yet another adaptation to improve recruitment and survival in the face of catastrophic events such as climate change, the loss of river habitat through the construction of culverts (MacPherson et al. 2012) or dams, and the introduction of exotic species such as Sea Lampreys and Alewives (Madenjian et al. 2002). In fact, multiple spawning behaviors and the widespread presence of juveniles throughout Michigan and parts of Wisconsin may explain why Burbot survived the Sea Lamprey invasion while Lake Trout were extirpated in all the Great Lakes except Lake Superior (Coble et al. 1990).

The source of most of the adult Burbot found in the Great Lakes is unknown. Adult Burbot from tributaries are usually small $(<300 \mathrm{~mm})$ but apparently abundant in some circum- stances. It is unknown whether any of these fish leave their natal tributaries as juveniles or adult fish but, as noted, juveniles have been captured in Sea Lamprey traps near the mouths of several rivers where sampling was ongoing. In the Great Lakes, winter spawners deposit eggs in nearshore and offshore sandy and rocky areas (Scott and Crossman 1973; Jude et al. 1979). In the nearshore zone there is higher productivity and temperatures favoring the survival of larval Burbot, but this advantage presumably comes with a higher mortality rate from predators, especially Alewives (Madenjian et al. 2002). Offshore water temperatures are colder and zooplankton prey are usually less abundant than nearshore (with the possible exception of the reefs, where currents and the elevated structure [sea mount] can concentrate both larvae and zooplankton prey). Does this increased diversity in spawning improve their adaptability, or do the deep reef Burbot become reproductively marooned, with larvae hatching too late for optimal survival? Which spawning areas (tributaries, nearshore sandy and rocky reefs, or offshore reefs) produce the most recruits is a question that may be important for managers trying to restore Burbot populations. This question should be addressed using genetic analyses or trace chemical or stable isotope analyses (Campana 1999) of otoliths.

\section{Dynamics of Temperature-Related Burbot Larvae Distribution}

With potential larval Burbot sources ranging from tributaries to extreme depths, there is an interesting question as to which source of larval Burbot recruits where and how water temperatures affect this relationship. Because Burbot inhabit a wide range of habitats with very different annual temperatures regimes, it is not surprising that the composite spawning season is quite long, perhaps in excess of half a year. The geographic variation in the temperature regime has certain surprises. For example, for the East Reef the warmest time of year at its 50-m summit is late November $\left(7-8^{\circ} \mathrm{C}\right)$, when the thermocline descends (Janssen et al. 2007). Consider the fate of a Burbot larva in a coastal stream flushed into the main basin in spring. For the four deepest Great Lakes (Superior, Michigan, Huron, and Ontario), coastal water begins warming, partially fed by tributaries, which warm more quickly. The offshore temperature is $<4^{\circ} \mathrm{C}$, and the nearshore water is physically separated from the coastal water by the sinking $4{ }^{\circ} \mathrm{C}$ water (the "thermal bar"). The coastal water is both warmer and more fertile than the offshore water, so the larvae in it are likely to grow faster. The thermal bar transitions first into a "thermal wedge" as the lake warms; final full-lake stratification is a consequence of local warming and offshore movement of the warmer coastal water. For Lake Michigan, the thermal bar generally is initiated in April and stratification may not be complete for a month. The process is most completely reviewed in Mortimer (2004), and a recent example is in Wang et al. (2012). Note that a Burbot larva originating in a tributary prior to the thermal bar period could be either flushed by lake currents well offshore into offshore water in which warming is well delayed or stay nearshore 
and experience much earlier warming within the thermal bar. The thermal bar/thermal wedge never reached as far as the Lake Michigan MLRC, so Burbot larvae emerging in the coastal zone must wait for complete stratification before transport to offshore deep water.

\section{Spatial Differences in Production of Burbot Larvae in Lake Michigan: East versus West}

There appear to be large differences in the distribution and occurrence of Burbot larvae on the eastern and western sides of Lake Michigan, since none were collected during extensive studies during thermal bar formation in April-May 20072009 on the western side, while great numbers of larvae (2$843 / 1,000 \mathrm{~m}^{3}$ ) were observed during March 29-June 29 in samples at power plant sites (Mansfield et al. 1983) and by Nash and Geffen (1991) during June-July (up to 18/1,000 $\mathrm{m}^{3}$ ) along the eastern side. More were found offshore than nearshore. Great numbers of larval Burbot were documented by Mansfield et al. (1983) on the western side of Lake Michigan at the Haven and Ozaukee sites north of the MLRC. Apparently few or no Burbot larvae originate from Wisconsin rivers in the southern part of Lake Michigan; this is substantiated by Becker (1983), who provide no records of juvenile or adult Burbot in tributaries into the main basin of Lake Michigan, south of Green Bay. However, Burbot larvae are present in sometimes high densities $\left(24,000 / 1,000 \mathrm{~m}^{3}\right.$; Mansfield et al. 1983) farther north of Milwaukee in Green Bay tributaries from April 27 to14 June 14. Some of the large (10-15-mm) Burbot larvae that we found on the midlake reefs during June 18-July 14 were thought to be spawned during winter, probably originating from these Green Bay rivers (e.g., tributaries like the Bark and Ford rivers). These large larvae could also have originated from or near the midlake reefs. In contrast, juvenile and adult Burbot are readily seen during scuba dives on the western side (which is more rocky) but not the eastern side (which is mostly sand). Burbot were found in 10-15 m of water along the Door Peninsula north of Sturgeon Bay and as shallow as $1 \mathrm{~m}$ during early autumn, or collected in gill nets out to at least $35 \mathrm{~m}$ in the vicinity of Milwaukee ( $\mathrm{J}$. Janssen, unpublished data).

\section{Effect of Currents on the Distribution of Burbot Larvae}

We found significantly more larval Burbot on the midlake reefs $(90.3 \%)$ than off the reefs in the coastal zone $(9.7 \%)$ during June and July. A possible reason for this finding is the probable spawning grounds on the reef and the concentration of fish larvae and zooplankton in the area by currents. For example, larval Deepwater Sculpin disappeared from the nearshore water column after stratification, a time when larval Yellow Perch also moved offshore with the currents (Dettmers et al. 2005). Lakewide current studies (Mortimer 2004; Beletsky et al. 2007) clearly show current patterns and the advection of particles from nearshore to offshore waters. Many hydrodynamic factors likely operate at the MLRC that either render it a profitable place for a larval fish to forage during stratification or physically aggregate larvae. Areas at which strong currents intercept areas of rapid shallowing (termed "abrupt topographies" in the oceanographic literature) can concentrate both zooplankton and fish (Genin 2004). Where measured, the currents at the MLRC can be strong (Gottlieb et al. 1989) and their upwelling is likely responsible for frequent thermal fronts there (Ullman et al. 1998). One mechanism discussed by Genin (2004) involves a behavioral response by zooplankton, i.e., to swim downward in an upwelling water mass to maintain a favored, light-determined depth preference. This could not only concentrate prey for larval Burbot but, because the Burbot migrate vertically, it could concentrate them. Houghton et al. (2010) proposed another mechanism that topographically traps vertically migrating Mysis during their dawn descent. In Lake Constance larval Burbot undergo a diel vertical migration with a range of about $10 \mathrm{~m}$ (nocturnal) to $70 \mathrm{~m}$ (daytime) (Probst and Eckmann 2009a, 2009b). If this occurs in the Great Lakes, the drifting larvae could settle and transition to their benthic phase when their drift encounters the bottom. Transitioning fish would likely concentrate at about $70 \mathrm{~m}$ not only along coasts but also at the MLRC and other offshore deep reefs such as Six-Fathom Bank and Yankee Shoals in Lake Huron. Interestingly enough, Nash and Geffen (1991) found that Deepwater Sculpin larvae on the eastern side of Lake Michigan became demersal in around 50-75 m, where adult prey Diporeia and Mysis were in high abundances.

\section{Settlement of Burbot Larvae to the Bottom}

No Burbot larvae greater than $15 \mathrm{~mm}$ were collected during this study; this is consistent with what Ghan and Sprules (1993) found in Oneida Lake and Miler and Fischer (2004) found in Lake Constance, although Clady (1976) reported maximum lengths of $20 \mathrm{~mm}$ in Oneida Lake studies while Oyadomari and Auer (2004) found maximum lengths of $17.3 \mathrm{~mm}$ in Lake Superior. We know that after hatching larvae emerge and go to the surface to fill their swim bladders and inhabit the pelagic zone (Ryder and Pesendorfer 1992). They perform a diel vertical migration during their 2-3 months in the pelagic zone (Wang and Appenzeller 1998; Miler and Fischer 2004), with the range of their migration increasing with their size, so that they were around the 10-m stratum during night feeding (Probst and Eckmann 2009a) while descending to $70 \mathrm{~m}$ during the day (Probst and Eckmann 2009b). At some point around 17-21 mm, they settle to the bottom in the profoundal zone (Miler and Fischer 2004) and move along the bottom to the littoral zone (Fischer 1999), usually in August and September (Fischer and Eckmann 1997). Clady (1976) reported that some demersal Burbot (44-70 mm) in Oneida Lake tended to move into and toward the mouth of tributary streams in summer. We have done extensive seining, trawling, and scuba diving on both sides of Lake Michigan for the last 40 years and have only seen one juvenile Burbot in a trawl offshore in deep water on the eastern side. In addition, a few were impinged on a power plant screen (Thurber and Jude 1985) on the eastern side (which is mostly sand), while moderate numbers of juvenile Burbot have been 
observed at natural and artificial reefs south of Milwaukee on the western side (which is more rocky). Some juveniles were also collected on the midlake reefs during ROV work there (Janssen et al. 2006), suggesting that some of the Burbot that become demersal stay on the reef rather than going toward shore. This suggests a preference for rocky habitat, which was also observed among inland river populations during electroshocking.

\section{Evolution of Spawning Strategies}

Because Burbot are the only completely freshwater gadid fish, the possible evolutionary routes to their having both lentic and lotic spawning, including in deepwater, are of interest. The Atlantic Tomcod is an anadromous gadid, which spawns during increasing spring flows in tidal rivers and thus can be considered a river-pulse spawner. River-pulse spawners include a diverse ensemble of fishes that time their spawning to coincide with spring floods; eggs and/or larvae drift with the current (Bayley 1995). For Atlantic Tomcod the drift is complicated by tidal cycles, but it may approximate an early stage of transition from the typical marine gadid spawning habit of having drifting eggs and larvae. Assuming that riverine spawning by Burbot is the ancestral mode of spawning, it appears that coastal and deepwater spawning is a transition back to the typical gadid marine spawning with drifting eggs being adapted for either river-pulse spawning or spawning in large lakes with oceanic hydrodynamic properties. The genus Coregonus, which includes river-pulse spawners whose larvae emerge during spring floods (Næsje et al. 1995), may offer a similar example in which the deepwater cisco ensembles were derived from shallow-water species.

Another species that may have undergone an evolution somewhat similar to that of the Burbot is the Fourhorn Sculpin Myoxocephalus quadricornis, which occupies shallow, Arctic, coastal water. The Deepwater Sculpin evolved from the common ancestor of Fourhorn Sculpins and Deepwater Sculpins and generally lives at depths $>70 \mathrm{~m}$ in the Great Lakes. Like the Fourhorn Sculpin, the Deepwater Sculpin has pelagic larvae (Mansfield et al. 1983; Geffen and Nash 1992), and it might be that the hydrodynamic conditions that promoted the evolution of pelagic larvae for the many diverse marine species also apply to large lakes. The role of hydrodynamics in the dispersal of Yellow Perch in Lake Michigan has recently been addressed by Dettmers et al. (2005) and Beletsky et al. (2007).

Recent work on rapid speciation in candelabrum corals $\mathrm{Eu}$ icea flexuosa suggests that it is worth examining the genetic divergence of deepwater from stream Burbot (Prada and Hellberg 2013). In the case of the corals, reefs were colonized by "inviable immigrants," individuals of a sibling coral species that experienced some survival of larvae after colonizing a reef deeper than that on which they originated but that were unable to mature and reproduce. The inviability was likely because the appropriate spawning cues were absent at the deeper reef. For Burbot, larvae originating from coastal streams and derived from parents that respond to riverine spawning cues may never reproduce if the necessary spawning cues are absent, even if they survive to settlement in an open Great Lake environment.

\section{ACKNOWLEDGMENTS}

We thank the Environmental Protection Agency, Great Lakes National Program Office, the Great Lakes Fishery Trust, and the Great Lakes Fishery Commission for funding the larval fish work. This work was also funded by the University of Wisconsin Sea Grant Institute under a grant from the National Oceanic and Atmospheric Administration, National Sea Grant College Program and the state of Wisconsin. Federal grant number NA06OAR417001, project number R/FI-I. The University of Michigan School of Natural Resources and Environment funded the collection of Burbot juveniles from the Muskegon River. We thank Michael Wiley for help with the Michigan River Inventory data set and our zooplankton/Mysis technicians for their care in removing larval fish from samples. Erin Burkett produced Figure 5 while Lacey Mason created Figure 1; we are indebted. Thanks to the reviewers and Martin Stapanian for critical comments.

\section{REFERENCES}

Auer, N. A., editor. 1982. Identification of larval fish of the Great Lakes Basin with emphasis on the Lake Michigan drainage. Great Lakes Fishery Commission, Special Publication 82-3, Ann Arbor, Michigan.

Bailey, M. M. 1972. Age, growth, reproduction, and food of the Burbot, Lota lota (Linnaeus), in southwestern Lake Superior. Transactions of the American Fisheries Society 101:667-674.

Bailey, R. M., W. C. Latta, and G. R. Smith. 2004. An atlas of Michigan fishes with keys and illustrations for their identification. University of Michigan Museum of Zoology Miscellaneous Publication 192.

Barbiero, R. P., M. Balcer, D. C. Rockwell, and M. L. Tuchman. 2009. Recent shifts in the crustacean zooplankton community in Lake Huron. Canadian Journal of Fisheries and Aquatic Sciences 66:816-828.

Barbiero, R., and M. Tuchman. 2001. Results from EPA's biological open water surveillance program in the Laurentian Great Lakes: I. Introduction and phytoplankton. Journal of Great Lakes Research 27:134-154.

Barbiero, R., and M. Tuchman. 2002. Results from the biological open water surveillance program of the Great Lakes 1999. U.S. Environmental Protection Agency, Great Lakes National Program Office, EPA-905-R, Chicago.

Barbiero, R., and M. Tuchman. 2004. Changes in the crustacean communities of Lakes Michigan, Huron, and Erie after the invasion of the predatory cladoceran Bythotrepes longimanus. Canadian Journal of Fisheries and Aquatic Sciences 61:2111-2118.

Bassett, C., and M. Herman. 2009. Whitefish River fishery status report. Michigan Department of Natural Resources, Lansing.

Bassett, C., and D. Kramer. 2009. Sturgeon River fishery status report. Michigan Department of Natural Resources, Lansing.

Bayley, P. B. 1995. Understanding large river-floodplain ecosystems. Bioscience 45:153-158.

Becker, George C. 1983. Fishes of Wisconsin. University of Wisconsin Press, Madison.

Beletsky, D., D. Mason, D. J. Schwab, E. Rutherford, J. Janssen, D. Clapp, and J. Dettmers. 2007. Biophysical model of larval Yellow Perch advection and settlement in Lake Michigan. Journal of Great Lakes Research 33:842-866.

Bjorn, E. E. 1939. Preliminary observations and experimental study of the Ling Lota maculosa (LeSeur), in Wyoming. Transactions of the American Fisheries Society 69:192-196. 
Boyer, L. F., R. A. Cooper, D. T. Long, and T. M. Askew. 1989. Burbot (Lota lota) biogenic sedimentary structures in Lake Superior. Journal of Great Lakes Research 15:174-185.

Campana, S. 1999. Chemistry and composition of fish otoliths: pathways, mechanisms and applications. Marine Ecology Progress Series 188:263-297.

Cardinale, M., J. Hjelm, and M. Casini. 2008. Disentangling the effect of adult biomass and temperature on the recruitment dynamics of fishes. Pages 231238 in G. H. Kruse, K. Drinkwater, J. N. Ianelli, J. S. Link, D. L. Stram, V. Westpestad, and D. Woodby, editors. Resiliency of gadid stocks to fishing and climate change. Alaska Sea Grant Program, QAK-SG-08-01, Fairbanks.

Clady, M. 1976. Distribution and abundance of larval Ciscoes, Coregonus artedii, and Burbot, Lota lota, in Oneida Lake. Journal of Great Lakes Research 2:234-247.

Coble, D., R. Bruesewitz, T. Fratt, and J. Scheirer. 1990. Lake Trout, Sea Lamprey, and overfishing in the upper Great Lakes: a review and reanalysis. Transactions of the American Fisheries Society 119:985-995.

Cushing, D. H. 1982. Climate and fisheries. Academic Press, New York.

Dettmers, J. M., J. Janssen, B. Pientka, R. S. Fulford, and D. J. Jude. 2005. Evidence across multiple scales for offshore transport of Yellow Perch (Perca flavescens) larvae in Lake Michigan. Canadian Journal of Fisheries and Aquatic Sciences 62:2683-2693.

Dixon, C. J., and J. C. Vokoun. 2009. Burbot resource selection in small streams near the southern extent of the species range. Ecology of Freshwater Fish 18:234-246.

Donner, M. T., and R. Eckmann. 2011. Diel vertical migration of larval and early juvenile Burbot optimizes survival and growth in a deep, pre-alpine lake. Freshwater Biology 56:916-925.

Edsall, T., G. Kennedy, and W. Horns. 1993. Distribution, abundance, and resting microhabitat of Burbot on Julian's Reef, southwestern Lake Michigan. Transactions of the American Fisheries Society 122:560-574.

Fischer, P. 1999. Otolith microstructure during the pelagic, settlement and benthic phases in Burbot. Journal of Fish Biology 54:1231-1243.

Fischer, P., and R. Eckmann. 1997. Seasonal changes in fish abundance, biomass, and species richness in the littoral zone of a large European lake, Lake Constance, Germany. Archiv fuer Hydrobiologia 139:433-448.

Fratt, T. W., D. W. Coble, F. Copes, and R. E. Bruesewitz. 1997. Diet of Burbot in Green Bay and western Lake Michigan with comparison to other waters. Journal of Great Lakes Research 23:1-10.

Geffen, A. J., and R. D. M. Nash. 1992. The life-history strategy of Deepwater Sculpin, Myoxocephalus thompsoni (Girard), in Lake Michigan: dispersal and settlement patterns during the first year of life. Journal of Fish Biology 41(Supplement B):101-110.

Genin, A. 2004. Bio-physical coupling in the formation of zooplankton and fish aggregations over abrupt topographies. Journal of Marine Systems 50:3-20.

Ghan, D., and W. Sprules. 1993. Diet, prey selection, and growth of larval and juvenile Burbot Lota lota (L). Journal of Fish Biology 42:47-64.

Gottlieb, E. S., J. Saylor, and G. Miller. 1989. Currents and temperatures observed in Lake Michigan from June 1982 to July 1983. NOAA Technical Memorandum ERL GLERL-71.

Hensler, S. R., D. J. Jude, and J. He. 2008. Burbot growth and diets in Lakes Michigan and Huron: an ongoing shift from native species to Round Gobies. Pages 91-110 in V. L. Paragamian and D. H. Bennett, editors. Burbot: ecology, management, and culture. American Fisheries Society, Symposium 59, Bethesda, Maryland.

Hofmann, N., and P. Fischer. 2001. Seasonal changes in abundance and age structure of Burbot Lota lota (L.) and Stone Loach Barbatula barbatula (L.) in the littoral zone of a large pre- alpine lake. Ecology of Freshwater Fish 10:21-25.

Houghton, C. J., C. R. Bronte, R. W. Paddock, and J. Janssen. 2010. Evidence for allochthonous prey delivery to Lake Michigan's mid-lake reef complex: are deep reefs analogs to oceanic sea mounts? Journal of Great Lakes Research 36:666-673.

Jacobs, G. R., C. P. Madenjian, D. B. Bunnell, and J. D. Holuszko. 2010. Diet of Lake Trout and Burbot in northern Lake Michigan during spring: evidence of ecological interaction. Journal of Great Lakes Research 36:312317.

Jäger, T., W. Nellen, W. Schofer, and F. Shodjai. 1981. Influence of salinity and temperature on early life stages of Coregonus albula, C. lavaretus, $R$. rutilus, and L. lota. Rapports et Proces-Verbaux de Reunions Conseil International pour l'Exploration de la Mer 178:345-348.

Janssen, J., D. Jude, T. Edsall, M. Paddock, N. Wattrus, M. Toneys, and P. McKee. 2006. Evidence of Lake Trout reproduction at Lake Michigan's mid-lake reef complex: hypotheses regarding the indigenous fish and implications for restoration. Journal of Great Lakes Research 32:749763.

Janssen, J., J. E. Marsden, C. Bronte, D. Jude, S. Sitar, and F. Goetz. 2007. Challenges to deepwater reproduction by Lake Trout: pertinence to restoration in Lake Michigan. Journal of Great Lakes Research 33(Supplement 1):5974.

Jones, M. L. K., G. W. Eck, D. O. Evans, M. C. Fabrizio, M. H. Hoff, P. Hudson, J. Janssen, D. Jude, R. O'Gorman, and J. F. Savino. 1995. Limitations to Lake Trout (Salvelinus namaycush) rehabilitation in the Great Lakes imposed by biotic interactions occurring at early life stages. Journal of Great Lakes Research 21(Supplement 1):505-517.

Jude, D. J., F. J. Tesar, and H. T. Tin. 1998. Spring distribution and abundance of larval fishes in the St. Marys River, with a note on potential effects of freighter traffic on survival of eggs and larvae. Journal of Great Lakes Research 24:569581 .

Jude, D., F. Tesar, J. Tomlinson, N. Thurber, T. Miller, J. Dorr III, and G. Godun. 1979. Inshore Lake Michigan fish populations near the D. C. Cook Nuclear Plant for preoperational years 1973-1974. Universityof Michigan, Great Lakes Research Division, Special Report 71, Ann Arbor.

Kallasvuo, M., M. Salnen, and A. Lappalainen. 2010. Does the zooplankton prey availability limit the larval habitats of pike in the Baltic Sea? Estuarine, Coastal and Shelf Science 86:148-156.

MacPherson, L., M. Sullivan, A. Foote, and C. Stevens. 2012. Effects of culverts on stream fish assemblages in the Alberta foothills. North American Journal of Fish Management 32:480-490.

Madenjian, C. P., G. L. Fahnenstiel, T. H. Johengen, T. F. Nalepa, H. A. Vanderploeg, G. W. Fleischer, P. J. Schneeberger, D. M. Benjamin, E. B. Smith, J. R. Bence, E. S. Rutherford, D. S. Lavis, D. M. Robertson, D. J. Jude, and M. P. Ebener. 2002. Dynamics of the Lake Michigan food web, 1970-2000. Canadian Journal of Fisheries and Aquatic Sciences 59:736-753.

Mansfield, P., D. Jude, D. Michaud, D. Brazo, and J. Gulvas. 1983. Distribution and abundance of larval Burbot, Lota lota, and Deepwater Sculpin, Myoxocephalus thompsoni, in Lake Michigan. Transactions of the American Fisheries Society 112:162-172.

Martin, N., and C. Olver. 1980. The Lake Charr Salvelinus namaycush. Pages 206-269 in E. Balon, editor. Charrs: salmonid fishes of the genus Salvelinus. Dr. W. Junk, The Hague, The Netherlands.

McCormick, M., and G. L. Fahnenstiel. 1999. Recent climatic trends in nearshore water temperatures in the St. Lawrence Great Lakes. Limnology and Oceanography 44:530-540.

McCrimmon, H. R. 1959. Observations on spawning of Burbot in Lake Simcoe, Ontario. Journal of Wildlife Management 23:2347-449.

MDNR (Michigan Department of Natural Resources). 1993. Rotenone survey of the Muskegon River in Osceola County (T17N 9W S11) during 5 August 1983. Michigan Department of Natural Resources, Fisheries Division Report, Lansing.

Miler, O., and P. Fischer. 2004. Distribution and onshore migration behaviour of Burbot larvae in Lake Constance, Germany. Journal of Fish Biology 64:176185.

Mortimer, C. 2004. Lake Michigan in motion: responses of an inland sea to weather, earth-spin, and human activities. University of Wisconsin Press, Madison.

Muth, K. 1973. Population dynamics and life history of Burbot Lota lota (Linnaeus), in Lake of the Woods, Minnesota. Doctoral dissertation. University of Minnesota, Minneapolis. 
Næsje, T., B. Jonssons, and J. Skurdal. 1995. Spring flood: a primary cue for hatching of river spawning Coregoninae. Canadian Journal of Fisheries and Aquatic Sciences 52:2190-2196.

Nash, R., and A. Geffen. 1991. Spatial and temporal changes in offshore larval fish assemblages in southeastern Lake Michigan. Journal of Great Lakes Research 17:25-32.

Oyadomari, J., and N. Auer. 2004. Inshore-offshore distribution of larval fishes in Lake Superior off the western coast of the Keweenaw Peninsula, Michigan. Journal of Great Lakes Research 30(Supplement 1):369-384.

Prada, C., and M. E. Hellberg. 2013 Long prereproductive selection and divergence by depth in a Caribbean candelabrum coral. Proceedings of the National Academy of Sciences of the USA 110:3961-3966.

Probst, W. N., and R. Eckmann. 2009a. Diet overlap between young-of-the-year perch, Perca fluviatilis L., and Burbot, Lota lota (L.), during early life-history stages. Ecology of Freshwater Fish 18:527-537.

Probst, W. N., and R. Eckmann. 2009b. The influence of light on the diel vertical migration of young-of-the-year Burbot Lota lota in Lake Constance. Journal of Fish Biology 74:150-166.

Rice, J. A., L. B. Crowder, and M. E. Holey. 1987. Exploration of mechanisms regulating larval survival in Coregonus hoyi: do otoliths ring true? Transactions of the American Fisheries Society 114:532-539.

Ryder, R. A., and J. Pesendorfer. 1992. Food, growth, habitat, and community interactions of young-of-the-year Burbot, Lota lota L., in a Precambrian shield lake. Hydrobiologia 243/244:211-227.

Scott, W. B., and E. J. Crossman. 1973. Freshwater fishes of Canada. Fisheries Research Board of Canada Bulletin 184.
Seelbach, P. W., and M. J. Wiley. 1997. Overview of the Michigan Rivers inventory project. Michigan Department of Natural Resources, Fisheries Technical Report 97-3, Ann Arbor.

Sideleva, V. G. 2003. The endemic fishes of Lake Baikal. Backhuys, Leiden, The Netherlands.

Stauffer, T., and W. Wagner. 1979. Fish predation on Lake Trout eggs and fry in the Great Lakes, 1973-1978. Michigan Department of Natural Resources, Report 1864, Lansing.

Steele, J. H. 1985. A comparison of terrestrial and marine ecological systems. Nature 313:355-358.

Thurber, N. J., and D. J. Jude. 1985. Impingement losses at the D. C. Cook Nuclear Power Plant during 1975-1982 with a discussion of factors responsible and possible impact on local populations. University of Michigan, Great Lakes Research Division, Special Report 115, Ann Arbor.

Ullman, D., J. Brown, P. Cornillon, and T. Mavor. 1998. Surface temperature fronts in the Great Lakes. Journal of Great Lakes Research 24:753-775.

Wang, N., and A. Appenzeller 1998. Abundance, depth distribution, diet composition and growth of perch (Perca fluviatilis) and Burbot (Lota lota) larvae and juveniles in the pelagic zone of Lake Constance. Ecology of Freshwater Fish 7:176-183.

Wang, Y., T. R. Consi, T. Hansen, and J. Janssen. 2012. The relationship between coastal Mysis diluviana abundance and spring thermal bar dynamics. Journal of Great Lakes Research 38(Supplement 2):68-72.

Wojcik, J., M. Evans, and D. Jude. 1982. Food of Deepwater Sculpin, Myoxocephalus thompsoni, from southeastern Lake Michigan. Journal of Great Lakes Research 12:225-231. 